\title{
Fondazione Telethon and Unione Italiana Lotta alla Distrofia Muscolare, a successful partnership for neuromuscular healthcare research of value for patients
}

\author{
Anna Ambrosini ${ }^{* *} \mathbb{D}$, Danila Baldessari ${ }^{1}$, Silvia Pozzi ${ }^{1,2}$, Manuela Battaglia', Elena Beltrami ${ }^{1}$, Anna Maria Merico ${ }^{1}$, \\ Marco Rasconi ${ }^{3}$ and Lucia Monaco ${ }^{1}$
}

\begin{abstract}
In 2001, Fondazione Telethon and the Italian muscular dystrophy patient organisation Unione Italiana Lotta alla Distrofia Muscolare joined their efforts to design and launch a call for grant applications specifically dedicated to clinical projects in the field of neuromuscular disorders. This strategic initiative, run regularly over the years and still ongoing, aims at supporting research with impact on the daily life of people with a neuromuscular condition and is centred on macro-priorities identified by the patient organisation. It is investigator-driven, and all proposals are peer-reviewed for quality and feasibility. Over the years, this funding program contributed to strengthening the activities of the Italian neuromuscular clinical network, reaching many achievements in healthcare research. Moreover, it has been an enabling factor for innovative therapy experimentation at international level and prepared the clinical ground to make therapies available to Italian patients. The ultimate scope of healthcare research is to ameliorate the delivery of care. In this paper, the achievements of the funded studies are analysed also from this viewpoint, to ascertain to which extent they have fulfilled the original goals established by the patient organisation. The evidence presented indicates that this has been a highly fruitful program. Factors that contributed to its success, lessons learned, challenges, and issues that remain to be addressed are discussed to provide practical examples of an experience that could inspire also other organizations active in the field of rare disease research.
\end{abstract}

Keywords: Neuromuscular disorders, Healthcare research, Patient empowerment, Trial readiness, Innovative therapies

\section{Background}

Fondazione Telethon (in brief: Telethon) is a non-profit organisation recognised by the Italian Ministry of Education, University and Research, that finances research on genetic diseases, focusing on those that for their rarity are not a priority in health policy and drug development [1]. It was founded in 1990 out of the will of the

\footnotetext{
*Correspondence: aambrosini@telethon.it

${ }^{1}$ Fondazione Telethon, Via Poerio 14, Milan, Italy

Full list of author information is available at the end of the article
}

Italian muscular dystrophy patient organisation (PO) Unione Italiana Lotta alla Distrofia Muscolare (UILDM), which urged to start research towards the cure of genetic muscular dystrophies and myopathies. The immediate success in fundraising prompted the Telethon Board of Directors in 1992 to extend its mission to all genetic diseases. Telethon's funding decisions are based on two principles: research must be scientifically excellent and must address the patients' mandate to develop a therapy for their disease and make it available to them. The fulfillment of this vision for the therapeutic approaches in original author(s) and the source, provide a link to the Creative Commons licence, and indicate if changes were made. The images or other third party material in this article are included in the article's Creative Commons licence, unless indicated otherwise in a credit line to the material. If material is not included in the article's Creative Commons licence and your intended use is not permitted by statutory regulation or exceeds the permitted use, you will need to obtain permission directly from the copyright holder. To view a copy of this licence, visit http://creativecommons.org/licenses/by/4.0/. The Creative Commons Public Domain Dedication waiver (http://creativeco mmons.org/publicdomain/zero/1.0/) applies to the data made available in this article, unless otherwise stated in a credit line to the data. 
the Telethon's pipeline that reached the clinical stage implied the development of strong business development and regulatory affairs competences. In 2010, Telethon established the first relevant partnership with industry (GlaxoSmithKline, "GSK"), leveraging the results of its investment in gene therapy started in 1995 with the creation of the San Raffaele-Telethon Institute for Gene Therapy in alliance with the San Raffaele Hospital in Milan. Such a multi-stakeholder collaborative approach was instrumental in completing the path starting from basic research to clinical studies and led in 2016 to the marketing authorization by the EMA for Strimvelis, a gene therapy for the treatment of adenosine deaminase deficiency immunodeficiency a rare monogenic disease. This was the first ex vivo gene therapy treatment ever approved [1]. At the end of 2020, Libmeldy, another gene therapy medicine derived from the Telethon's pipeline, was approved by the European Medicine Agency for treatment of children with metachromatic leukodystrophy [2]. Four other gene therapy treatments are in the Telethon clinical pipeline (not shown). Overall, 130 patients from 32 different countries have been treated with these gene therapy approaches.

Despite the expansion of its mission to all rare genetic diseases and the development of successful gene therapy programs, neuromuscular disorders (NMDs) have always remained at the heart of the Foundation's objectives, with a total investment of about 125 million Euros in this research area (about $23 \%$ of total investment).

NMDs are a highly heterogeneous group of diseases, in terms of epidemiology, genetics, molecular physiopathological mechanisms, and clinical phenotypes [3, 4]. When, in the late nineties, the gene therapy programs at Telethon entered a new age for those diseases for which hematopoietic stem cell correction was feasible [1], it became clear that this therapeutic strategy would not be easily translatable to NMDs. First of all, such gene therapy protocol was not suitable for muscular dystrophies, where the genetic correction must be delivered directly to the muscle tissue. Moreover, in the late nineties the understanding of the mechanisms of muscle degeneration/regeneration mechanisms was still quite limited, as was the clinical knowledge of the different NMDs. At that time, Telethon-supported NMD research was primarily seeking to fill this gap through basic studies focused on gene discovery and mechanistic understanding of the muscle physiopathology. Clinical study designs suffered from important limitations, mainly due to a lack of knowledge of natural history and availability of appropriate functional measures, as well as to insufficient statistical power and poor networking to overcome these problems. Overall, this research was very far from having a significant impact on people affected by muscular dystrophy. Clearly, the NMD field required a research strategy different from the path developed for the Telethon gene therapy programs and UILDM strongly called for a new approach to address patient needs.

To address the above limitations, Telethon and UILDM together designed a call for clinical research grants exclusively dedicated to research aimed at improving the quality of life (QoL) of people living with a neuromuscular condition. In 2001, Telethon launched the first call of this program and has since issued it regularly, with UILDM providing annual financial support of around 600,000 euros. This program has also attracted additional funds from other patient organisations and pharmaceutical companies interested in the NMD field. At the end of 2020 , the total investment in this strategic program was 12.37 million euros.

Over the years, this initiative has been instrumental to translate clinical observations into healthcare practice and implement a holistic approach to the person's medical needs. Furthermore, the results of the TelethonUILDM clinical grant investment have been enabling factors for the translation of innovative therapeutic approaches developed by international pharmaceutical companies into clinical research and therapies, now available to patients.

This paper focuses on the research management model adopted by Telethon for this special program, from the rigorous peer review to select excellent clinical projects to the lessons learned in managing the grants, particularly those dedicated to multicentre projects. The impact of the increased clinical knowledge on patient care and on the development of the NEuroMuscular Omni (NEMO) centres, multispecialty clinical centres fully dedicated to patients with NMDs [5, 6], is discussed, as well as the facilitating role of this gained knowledge for the implementation of innovative therapies. The key factors that contributed to the success of this program and issues that still require consideration are analysed. This experience is shared in the hope that it will also inspire other charities and POs interested in funding clinical research on NMDs or, more generally, on rare diseases.

\section{Methodology}

\section{Project selection and management}

Applications submitted to the Telethon-UILDM Calls for NMD clinical projects underwent a rigorous peer-review evaluation, involving international clinical experts. Advice from consultants with expertise in biostatistics was made available to interested investigators to improve the study design during the preparation of the applications. Occasionally, additional grants were awarded to the NMD clinical network with financial support from other NMD POs or pharmaceutical companies; these 
ad hoc sponsored projects also underwent a rigorous peer review to assess their scientific quality and feasibility before awarding grants. Periodic analyses were conducted by the Telethon scientific office to identify critical issues in the management of the funded projects and implement corrective actions to counter failures or prevent those threats that mainly affect multicentre studies' performance. The focus of the call was also periodically revisited together with UILDM.

\section{Bibliometric analysis}

A total of 354 publications (original articles, letters and brief case reports, and reviews) acknowledging the Telethon-UILDM studies and/or the other related ad hoc clinical grants was indexed through 2021-01-31 (source: Telethon publications' database, powered via the Web of Science Core Collection ${ }^{\text {TM }}$ onto the Web of Science platform by Clarivate ${ }^{\mathrm{TM}}$ [7] and via the Europe PubMed Central platform [8]; last access to both 2021-02-26). The original articles and the reviews (348 publications) underwent a bibliometric analysis based on the relative citation ratio (RCR), a metric developed by the National Institutes of Health (NIH) Office of Portfolio Analysis [9]. RCR is an article-level metric calculated as the number of cites per year of each paper, normalized to the citations per year received by NIH-funded papers in the same field. Fields are sampled for each article by using its cocitation network. The RCR values are provided through the $i$ Cite web interface made available by NIH [10]. The RCR value of 320 of the 348 publications was available on the NIH platform, being the other 28 papers too recent or lacking the PubMed Identifier required for the analysis (values calculated on 2021-03-19).

Some key publications acknowledging the funded studies are presented in more detail in the Results and Discussion sections. The selection was based on one or more of the following criteria: i) relevance for the topic discussed; ii) tangible evidence of healthcare implementation; iii) pivotal paper or most recent publication of the author on the topic; iv) RCR value above 1 (if available).

\section{Classification of the medical fields and topics}

The assignment of the main field category and specific topics of each project is based on the keywords indicated by the principal investigators in their original application, chosen from among a set of medical fields and research topics provided within the Application form, and subsequently validated by the Telethon scientific office.

\section{Customer satisfaction of patients admitted to the NEMO centres}

Aggregated data from Customer Satisfaction questionnaires of the NEMO centres were available online within their most recent annual Impact Report referring to the year 2019 (pages 41 to 45) [6]. In that Report, items based on a standard scale were grouped according to specific areas of the patient's perceived quality of care and average scores were given based on a ranking that was calculated by the NEMO professionals over a range of $1-10$ [6]. These results are herein briefly reported together with the NEMO vision illustrated at page 12 of the same Impact Report (after translation in English and back translation for content validation) [6].

\section{Results}

\section{A call for grant applications to prioritise NMD healthcare research}

The Telethon-UILDM Call initiative has been dedicated to NMD healthcare research aimed at improving patient daily life. UILDM representatives identified the main topics of interest to them and defined the research priorities, which were periodically revised, while the Telethon research managers implemented rigorous methods for the selection and monitoring of the projects. The strategic definition of the program also benefited from the advice of international experts in the NMD clinical field. The call for projects aimed at developing diagnostic, preventive, therapeutic and rehabilitative approaches for NMD of genetic origin in the following main medical areas of interest: cardiology, internal medicine, neurology, orthopaedics, psychology and respiratory medicine. Other topics that UILDM considered to be of great relevance concerned assistance outside the hospital context, and support and training to caregivers. Collaboration between different clinical centres and participation in multicentre studies have always been strongly encouraged. The quality of grant applications, as measured by the calls' success rate, has significantly improved over the years, also thanks to the methodological support offered by Telethon and the careful evaluation and the constructive suggestions provided by the reviewers to the applicants. In the period 2001-2019, 14 calls were issued, with a total of 56 grants awarded. The average number of applications received per call was 13 (range 9-20; median 14 ), with 4 projects (range 2-6; median 4) approved for funding (mean success rate of $30 \%$ ). Five additional ad hoc grants were also awarded to consolidated projects after a rigorous peer review evaluation, to provide continuity to the ongoing clinical research. These 5 granted projects have also been included in the analysis herein presented. The total investment in this program has been 12.37 million euros.

Among the 61 granted projects, 46 were collaborative studies, with a mean number of 8 clinical centres per multicentre project (number of centres in the range $2-15$; median 8 ). Overall, 44 tertiary clinical centres in 
Italy (Fig. 1) and 120 principal investigators actively participated in these projects.

As expected, neurologists represented the vast majority of specialists involved. Nevertheless, other experts participated in many projects, both as coordinators (cardiologists, endocrinologists, medical geneticists, nutritionists,

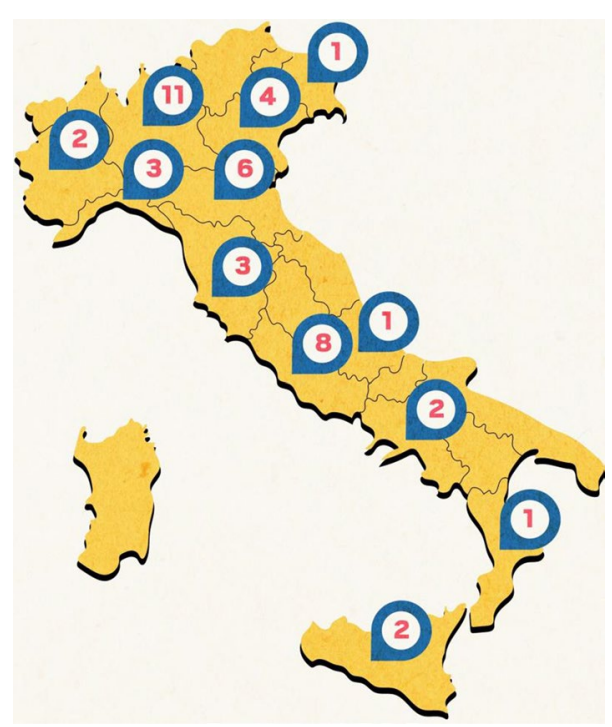

Fig. 1 Distribution of the Italian NMD clinical centres awarded with Telethon-UILDM grants. In circles: number of centres per region psychiatrists, psychologists, or bioengineers), and as partners (pulmonologists, radiologists, experts in sleep medicine, or biostatisticians).

After grant approval, Telethon carefully managed funds and monitored the performance of the projects, with special attention to the multicentre efforts. Continuous dialogue with the project coordinator and periodic analyses allowed to identify several critical issues, which were mainly related to: (i) extension of trial duration; (ii) lack of standardisation of operations and differences in the adoption of standards of care among centres; (iii) centre over-commitment across multiple projects (Table 1 ). Corrective actions were put in place by Telethon to counteract failures or prevent those threats that mainly affect multicentre studies, adopting more stringent eligibility criteria within the calls and better-defined administrative rules, and working closer to the coordinators to support their project management (see a few examples in Table 1). This process greatly contributed to harmonising the networking activities and fostered a cultural shift towards best practices in clinical research and data sharing.

\section{Diseases and medical fields addressed by the funded projects}

In general, each study addressed a single disease/disease group, with dedicated clinical working groups, who have also been successful in obtaining follow up grants

Table 1 Telethon management of criticalities in the conduct of multicentre clinical trials

\begin{tabular}{|c|c|}
\hline Critical issues (causes and consequences) & Actions taken \\
\hline Extension of trial duration & Administrative management of the grant \\
\hline * Time lag among centres for Ethics Board approval & Start of the study only when all centres are ready \\
\hline * Difficulties in patients' enrolment & \multirow{3}{*}{$\begin{array}{l}\text { Administrative distinction between start-up/follow up (fixed) costs and } \\
\text { "per patient" (variable) costs, with funds on variable costs allocated only to } \\
\text { performing centres, based on periodic reports on patient enrolment and } \\
\text { follow-up }\end{array}$} \\
\hline ** Expanded recruitment time and length of the study & \\
\hline $\begin{array}{l}\text { ** Insufficient statistical power; inclusion of additional centres; protocol } \\
\text { amendments; lack of funds }\end{array}$ & \\
\hline Lack of standardisation of operations & Management support to Coordinator \\
\hline * Uneven execution of functional measurements between centres & Clinical monitor support and good clinical practice compliance assessment \\
\hline * Unequal data quality and poor case report form maintenance & $\begin{array}{l}\text { Request for stronger coordinator management and training on outcome } \\
\text { measures and data collection }\end{array}$ \\
\hline * Poor awareness of data protection principles & Regular periodic meetings with the study steering committee \\
\hline ** Clinical data provided by the centres not comparable & Regular periodic reports to Telethon \\
\hline ** Lack of secure centralised systems for data management & $\begin{array}{l}\text { Centralised IT platform available for patient registries and standard operat- } \\
\text { ing procedures for data sharing }\end{array}$ \\
\hline Centres'over-commitment & Rules of the grant applications \\
\hline * Lack of dedicated personnel & $\begin{array}{l}\text { Limitation in the number of active studies in which an investigator can } \\
\text { participate }\end{array}$ \\
\hline * Overlap with routine clinical activities & \multirow{2}{*}{$\begin{array}{l}\text { Cross-check of the number of staff full time equivalents reported in the } \\
\text { applications }\end{array}$} \\
\hline $\begin{array}{l}\text { ** Inadequate number of professionals to ensure patient follow-up on } \\
\text { schedule }\end{array}$ & \\
\hline
\end{tabular}

In the column "Critical issues": *Indicates "cause", ** Indicates "consequence" 
through this funding program and have progressed on trial readiness in their specific field. Duchenne muscular dystrophy (DMD) and Charcot-Marie-Tooth disease (CMT) were the most studied diseases, followed by muscle glycogenoses and subgroups of muscular dystrophies other than DMD and spinal muscular atrophy (SMA) (Fig. 2).

Only 5 studies focused on more than one disease group, addressing the development and the validation of functional outcome measures (OM) or QoL scales across different conditions (Fig. 2).

Overall, more than 6000 patients were involved in these studies. At the time of submission of this manuscript 5 studies, all multicentre ones, were ongoing.
The funded projects addressed different medical fields, namely: cardiology, endocrinology and nutrition, genetics, neurology, physical medicine and rehabilitation, and psychology and QoL. Table 2 reports the main topics addressed within each area, the number of funded projects and the number of derived peer-reviewed publications.

\section{Bibliometric analysis}

Overall, the projects generated a comprehensive body of information, testified by 354 peer-reviewed publications (Web of Science platform by Clarivate ${ }^{\mathrm{TM}}$ and Europe PubMed Central $[7,8]$, including original articles $(n=316)$, letters and brief case reports $(n=6)$, and reviews $(n=32)$ (Table 2).

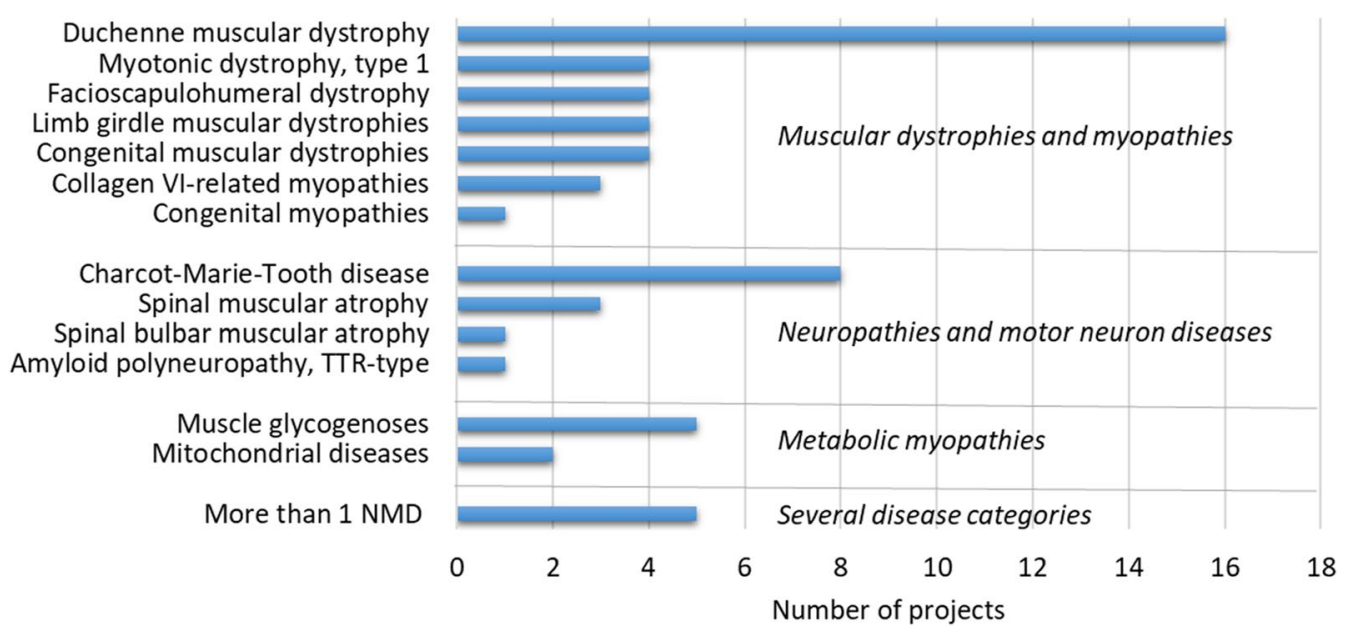

Fig. 2 Diseases addressed by the funded projects. The graph indicates the number of projects addressing a specific disease/disease group or multiple diseases. Diseases are organised into 4 main broad categories, namely: (i) muscular dystrophies and myopathies; (ii) neuropathies and motor neuron diseases; (iii) metabolic myopathies; (iv) several diseases. NMD neuromuscular disorder; TTR transthyretin

Table 2 Medical fields and main topics addressed by the funded projects

\begin{tabular}{|c|c|c|c|}
\hline Medical field & Main topics & $\begin{array}{l}\text { No. of } \\
\text { projects }\end{array}$ & $\begin{array}{l}\text { No. publications; Period: } 2004-2020 \text { (Sources: } \\
\text { Web of Science platforms by Clarivate }{ }^{\mathrm{TM}} \text { and } \\
\text { Europe PubMed Central) }\end{array}$ \\
\hline Cardiology & $\begin{array}{l}\text { Diagnosis; prevention; device; precision medicine; } \\
\text { biobanks }\end{array}$ & 4 & 13 \\
\hline Endocrinology and nutrition & $\begin{array}{l}\text { Bone density; body mass index; body composition; } \\
\text { dietary }\end{array}$ & 3 & 7 \\
\hline Medical genetics & Genetic diagnosis; gene panels & 7 & 53 \\
\hline Neurology & $\begin{array}{l}\text { Geno-phenotype correlation; functional outcome } \\
\text { measures; natural history; standards of care; phar- } \\
\text { macological trials }\end{array}$ & 38 & 240 \\
\hline Physical medicine \& rehabilitation & Exercise training; assistive technology & 4 & 21 \\
\hline Psychology and quality of life & $\begin{array}{l}\text { Quality of life questionnaires; caregiver burden; } \\
\text { neuropsychological and psychiatric evaluation }\end{array}$ & 5 & 20 \\
\hline
\end{tabular}


Bibliometric analysis was performed on original papers and reviews only. Telethon signed and endorses the San Francisco Declaration on Research Assessment (DORA) [11] and does not apply journal-based metrics even to assess candidates applying to its call for grant applications. Instead, the RCR metric of the NIH Portfolio office [9] was adopted as indicator of scientific influence in our bibliometric analysis. This metric is article-level and field-independent and identifies publications that are influential in the peer co-citation network, against a benchmark of papers derived from NIH projects, where $\mathrm{RCR} \geq 1.0$ and $\geq 2.0$ correspond to the NIH top $50 \%$ and $25 \%$ respectively. The RCR values of 320 publications (original articles and reviews) were available on the NIH $i$ Cite web platform [10]. RCR mean was $1.69+/-0.12$ and median 1.1, with 180 publications having RCR $>1.0$, including 81 with $\mathrm{RCR}>2.0$. Overall, these numbers suggest that, as a whole, the publications derived from Telethon-UILDM and the other related ad hoc clinical projects performed similarly or slightly better than the NIH benchmark in terms of influence on their peer community, with $56 \%$ and $25 \%$ of them falling in the $\mathrm{NIH}$ top $50 \%$ and $25 \%$ respectively. A striking difference was noted between original articles (RCR mean $1.47+/-0.08$ and median 1.06; $\mathrm{n}=288$ ) and reviews (RCR mean $3.63+/-0.89$ and median $=1.62 ; \mathrm{n}=32$ ). We also evaluated if RCR of publications in the different medical fields were comparable. Although for some of them the total number of projects - and acknowledging paperswas low, it is interesting to note that the RCR mean and median were above 1 for all groups but one, suggesting comparable publication recognition across the medical fields (Table 3 ), with a notable 1.88 mean RCR value for the neurology field, gathering two thirds of the publications analysed.

The relatively higher number of publications from projects in this field (220) allowed additional analysis, which was separately conducted on original articles and reviews. The percentage of papers with $\mathrm{RCR} \geq 1.0$ was $56 \%(n=125$ of 220$)$, in line with the whole publications' analysis. Interestingly, the RCR of the reviews was 4.31, a value which falls in the NIH top $10 \%$ (Table 4). Among them, 7 reviews scored above 4 (RCR range 5.16-26.02; median 8.66), with 6 having the Telethon principal investigator as first or last author (not shown). Overall, 57 publications in the "neurology" field derived from international collaborations, 41 of which with the Italian principal investigator as first or last author (Table 4), attesting the key role of the Telethon-funded investigators also in the international context.

\section{Outcomes of the studies}

Projects dedicated to genetic diagnosis and geno-phenotype correlation led to the characterization of large disease-specific patient cohorts [12-20]. In addition to increasing disease knowledge, these studies contributed

Table 3 RCR values of publications grouped by medical field of the projects

\begin{tabular}{llll}
\hline Medical fields & RCR mean +/-sem & RCR median & $\begin{array}{l}\text { No. indexed publications; } \\
\text { Period: 2003-2020 (source: } \\
\text { iCite) }\end{array}$ \\
\hline Cardiology & & 0.91 & 9 \\
Endocrinology and nutrition & $0.93+/-0.15$ & 1.22 & 5 \\
Medical genetics & $2.09+/-0.60$ & 1.04 & 50 \\
Neurology & $1.27+/-0.16$ & 1.15 & 220 \\
Physical medicine and rehabilitation & $1.88+/-0.17$ & 1.01 & 20 \\
Psychology and quality of life & $1.17+/-0.13$ & 1.1 & 16 \\
\hline
\end{tabular}

$R C R$ relative citation ratio

Table 4 RCR values of original articles and reviews in the field of neurology

\begin{tabular}{|c|c|c|}
\hline & Original articles $(n=197)$ & Reviews $(n=23)$ \\
\hline Mean $R C R+/-$ sem & $1.61+/-0.12$ & $4.31+/-1.19$ \\
\hline Publications with RCR $\geq 1.0$ (NIH top 50\%) & 107 & 18 \\
\hline Publications with RCR $\geq 4.0$ (NIH top 10\%) & 14 & 7 \\
\hline International collaborative papers & 48 & 9 \\
\hline Italian authorship in International collaborative papers & 36 & 5 \\
\hline
\end{tabular}

$N I H$ National Institutes of Health (USA), RCR relative citation ratio 
to identifying patients and families still missing a genetic diagnosis that underwent new genetic examination, with many families receiving appropriate genetic counselling [21-24]. Some studies allowed the identification of life-threatening risks, such as the mutations in the transthyretin (TTR) gene, which cause familial amyloidosis with severe cardiological and neurological dysfunctions [25]. The genetic testing of proband's relatives and the adoption of good practices to monitor even subtle clinical changes in asymptomatic carriers are particularly relevant for familial amyloidosis of TTR-type given the recent availability of effective innovative treatments [26].

The functional studies contributed to the timely update of OM under the umbrella of international consortia such as the Translational Research in Europe-Assessment and Treatment of NeuroMuscular Diseases (TREATNMD) network [27-29] and the Inherited Neuropathy Consortium [30-32], or promoted the development of new patient-centric $\mathrm{OM}$ with the direct involvement of patients and POs in their definition [33-35]. In addition to being adopted as functional endpoints in international trials [36, 37], these measures have been used to monitor current treatments [38] and were introduced into clinical routine practice, becoming a relevant tool as part of the standards of care [39].

Other studies addressed specific daily life needs, exploring QoL and caregiver burden of people with NMDs [40,41] or gathering information on nutrition and body composition, neuropsychological evaluation, physical exercise, pulmonary function, sleep disturbance, etc. (Table 1). In general, these were multicentre projects and involved specialists other than neurologists. Innovative studies based on brain-computer interface, gate analysis or exoskeletal devices were designed and implemented by neurologists and biomedical engineers working in close collaboration with patient groups. This approach was established upfront and was included in the design of the proposed applications.

A few clinical trials testing the efficacy of small molecules were also supported through this funding program. These concerned: a double-blind randomized, placebo-controlled, pilot trial of Ramipril in McArdle's disease [42]; a double-blind randomised ascorbic acid in CMT type 1A [43]; an open study on combined enzyme enhancement therapy and enzyme replacement therapy in Pompe disease [44]; a pilot open study in Collagen VIrelated myopathies with Cyclosporine A [45].

\section{Registries and real-world data from approved treatments}

Clinical data contributing to define the disease natural history have been collected within highly structured patient registries [46], based on an information technology platform deployed according to a privacy by design model compliant with the current European General Data Protection Regulation 2016/679 [47]. The data stewardship is held by a legal entity including Telethon, UILDM and other Italian NMD POs and is based on transparent governance and data use agreements with the involved clinical centres [48]. Distinct datasets collect genetic and clinical information on SMA, CMT, familial amyloidosis of TTR-type, muscle glycogenoses, spinal and bulbar muscular atrophy, congenital myopathies, and muscular dystrophies (congenital, limb girdle, and facio-scapulo-humeral dystrophy types). These registries include both clinician-reported $[25,48]$ and patientreported $[49,50]$ forms. Aggregated data derived from the NMD registry were also provided to industry for feasibility studies, establishing a transparent process of data sharing that contributes to the registry sustainability (unpublished). Moreover, in 2018 this platform has been made available to clinicians for post-marketing SMA data collection. Another registry on mitochondrial disorders was started with a Telethon-UILDM grant and is managed directly by Mitocon, the Italian mitochondrial PO, on a different information technology platform [51]; its data already contributed to several studies and publications (see, for example, refs [15] and [52]).

\section{Natural history data to support industry trial design and interpretation of study results}

Thanks to the support of several consecutive TelethonUILDM grants, the Italian clinical network collected longitudinal clinical and functional data from a large cohort of children with DMD, which helped define the natural history of this disease. These data contributed to steering the international discussion on DMD therapy approval with all DMD stakeholders and with regulators [36, 53]. The availability of this accurate data collection attracted the interest of pharmaceutical companies engaged in the development of new therapeutic approaches for DMD. The experience gained by Telethon in its previous relationship with industrial partners was instrumental in establishing data use agreements for nonexclusive use of anonymised patient data by companies (not shown) or by the "collaborative Trajectory Analysis Project" (cTAP), a pre-competitive coalition of different DMD stakeholders aimed at understanding the high variability in clinical trial outcomes [54]. Notably, the trajectories of ambulatory function measured by the 6 -min walking distance test have been used in an international context to define the best statistical model to represent natural history and explain the variability in disease progression [54]. The resulting patients' subgrouping, which considers age, steroid use and 6-min walking distance baseline values, can help explain variations in trial results and support future trial design [54]. Functional trajectories derived 
from the Italian DMD natural history studies also helped establish that disease progression differs in patients with different deletions amenable to different exon skipping [55]. Moreover, they have been recently used for metaanalyses also including cohorts of DMD patients from other countries, demonstrating that data derived from real-world and natural history are comparable with those collected in the placebo arms of 6 different trials [56]. Based on this evidence, the authors further suggested that natural history/real world data of patients could be considered as external controls in trials, thus avoiding the use of a placebo group, when patients are matched for genetic and clinical characteristics, and the same standards of care are adopted [56].

\section{Implementation of standards of care}

The synergistic activity among the Italian NMD clinical centres promoted by the Telethon-UILDM grants and the concomitant participation of this clinical network in international research efforts contributed to disseminating among the tertiary clinical centres the most updated guidelines on standards of care, where available [57-59], highlighting the need of implementing a multidisciplinary, patient-centric, approach to patient care.

In line with this holistic approach, in 2007 UILDM and Telethon promoted a new clinical centre model, fully dedicated to patients with NMDs, the NEMO centre, which is now operating through 6 centres located in different parts of Italy $[5,6]$. These clinical centres are based on a public-private model and on a governance that includes NMD POs to guarantees greater flexibility in the priority setting and management. The vision of the NEMO centres is "based on the need for a global and continuous care of the patient, both in adult and pediatric age, with a view to achieving the best quality of possible life, through personalized rehabilitation programs. Everything revolves around the person and his family. That's why the NeMO center is not only a place of care, but also a home where people of all ages and their families are welcomed, to listen, support and accompany them throughout their life path" [6]. The NEMO centres collect the voice of patients and their perceived impact of care through Customer Satisfaction questionnaires, the most recent data of which are reported in the NEMO annual Impact Report 2019 in aggregated form [6]. A very high score (9 or higher in a scale 1-10) was assigned by patients to all groups of items, namely: (a) patient-centricity; (b) trust in medical competence; (c) two-way dialogue; (d) continuity and home care support; (e) time in waiting list [6]. The NEMO centres have also participated in many of the clinical research projects herein described, either as coordinators or partners.
Several centres of the Italian NMD clinical network participate in the European Reference Network for Rare Neuromuscular Disease (Euro-NMD ERN), aimed at "harmonizing and implementing standards for clinical and diagnostic best practice, improving equity of care provision" across Europe [60].

\section{Discussion}

The value of an investment in biomedical research should be estimated by measuring the level of excellence and innovation of its outcomes, ultimately leading to effective medications accessible to patients [61]. This is also the vision of Telethon, which for the past 20 years has worked to make gene therapy treatments in its pipeline accessible to patients $[1,2]$. Fulfilling the mandate of patients affected by NMDs, however, has implied developing a different program of investments, aimed primarily at addressing the daily life demands of people with a neuromuscular condition. While the scientific quality of the clinical research proposed by the investigators was a key requirement for the funding decision, it was more difficult to identify the right indicators to measure the excellence of outcomes of this research-based health program that addressed medical needs of everyday life. On the one hand, health research may not imply innovative science, while retaining its important value for patients. On the other hand, there is a research-to-practice gap between the evidence produced by healthcare research and its effective translation into practice to improve patient care and treatments $[62,63]$. How, then, to evaluate the effectiveness of a strategic program such as the one herein described in terms of excellence and ability to achieve its original objectives? The research outcomes have been analysed from two different angles, the impact on clinical knowledge and the impact on patients' daily life, two sides of the same coin, as their value to patients should ultimately converge.

\section{Harmonisation of clinical research activities}

Through the years, the community of the Italian clinicians has responded with great interest to the Telethon and UILDM joint call to action and, undoubtedly, the program produced significant outcomes and cultural changes. Thanks to this initiative, a strong clinical network, which includes most of Italian NMD tertiary clinical centres, has been consolidated (Fig. 1). Clinical scientists have strengthened their research on different NMDs (Fig. 2) and contributed to NMD trial readiness in a timely fashion against the international scenario or even anticipating research needs, for instance regarding development and validation of OM [28, 29, 31-35]. They engaged in longitudinal data collection to increase knowledge on natural history for several NMDs, and 
standardised methods to evaluate patients [36-39]. They identified and challenged new pharmacological [42-45] or physical [31] therapy approaches and collected information on psychosocial burden to implement support actions $[41,50]$. By presenting the ongoing results during the scientific meetings and POs' congresses, they promoted the sharing of information and new ideas. Moreover, through dissemination of the outcomes of these studies, they have contributed to building international consensus on clinical trial design and standards of care guidelines. A large number of peer-reviewed publications was produced, with relatively high RCR scores, which are indicators of a strong influence on the NMD peer community (Tables 1, 2, 3, 4).

\section{The value for patients}

Looking at numbers and publications is not enough to establish the real value of healthcare research, whose ultimate scope is to be translated into practice and improve patient QoL [62, 63]. This investment was therefore evaluated for its impact on patients, by analysing to which extent the outcomes of the granted studies have been translated into medical practice or have promoted the development of innovative therapies. Figure 3 summarizes the domains that may contribute to creating value for patients, either directly (circles) or through an indirect, albeit relevant, manner (small arrows). For each domain strengths and open issues are highlighted below.

\section{Impact on diagnosis}

The genetic and clinical characterisation of large patient cohorts has had a broad impact nationwide on providing genetic diagnosis, inform about prognosis, and facilitate genetic counselling and decision making [12-25]. The investment in genomic research allowed to identify new mutations and new genes not yet included in the genetic services provided by the national health system, exploring what Horton and Lucassen defined "a hybrid space where clinical practice and research need to co-exist" [64]. Progress in molecular diagnosis has also benefited from nationwide sharing of information and patients' samples carried out by centres as part of the projects' activity. Despite these achievements, however, many patients/families still wait for the molecular characterization of their disease $[65,66]$. Patients with late-onset/ slow-progression forms may also miss a competent tertiary centre, thus experiencing diagnostic delay even in case of well-characterized diseases such as SMA [67]. Furthermore, available information on diagnosis and prognosis is essential but not sufficient for real shared decision-making, if effective communication is not established between healthcare professionals and their patients; much remains to be done both by professionals and POs to promote together this cultural change [62, 68].

\section{Patient-centricity}

With this particular investment, Telethon and UILDM meant to stimulate clinical researchers to approach medical research in a more person-centred manner. Some studies directly involved patients and caregivers, for instance, engaging them in surveys on QoL, disease burden and needs for psychosocial support [40, 41, 50], and collection of information on their medical requirements $[15,49,52]$. POs focused on DMD and their patient representatives participated in the development of a new functional scale that reflects patient mobility needs and daily life activities $[33,34]$ and patient-reported functional OM [35]. These are examples of a general trend of direct consultation with POs and patients during study design and delivery that has become more frequent, although it is not the norm yet [68].

\section{Transforming research into care}

To carry out careful natural history studies, more sensitive functional measures to monitor disease progression had to be developed and up to date standards of care implemented to standardise patient evaluation among centres. Consequently, best care practices have been disseminated nationwide and the centres participating in

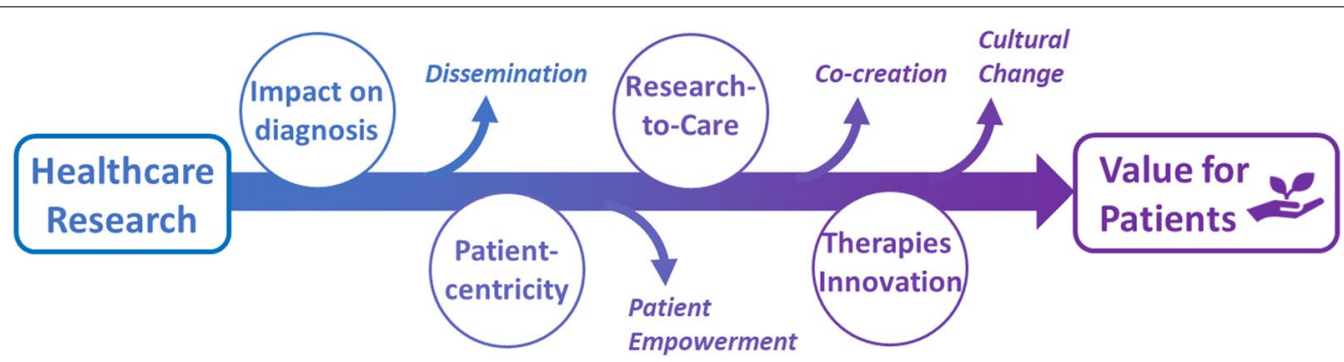

Fig. 3 Domains that concur to evaluate the value of the investment in healthcare research. In circles: domains with direct impact; indicated by the small arrows: domains of indirect impact 
the studies became familiar with them, supported also by disease-specific clinical care guidelines derived from international consensus [57-59].

Although also these guidelines emphasise the need for multidisciplinary care in the management of patient with NMDs, the degree of its actual implementation still varies from centre to centre. One reason is that putting it into practice is often beyond the doctor's willingness, as this process can also depend on additional factors, such as organizational norms, local and regional health policies, and policymaker decisions [63]. For these reasons, UILDM and Telethon in 2007 founded the NEMO clinics fully dedicated to patients with NMDs, which now count 6 active centres in Italy $[5,6]$. The NEMO centres are built on the concept of multidisciplinary care and person-centric holistic approach and have a high index of appreciation by patients for the care provided [6]. Although they work towards full integration of clinical research and medical care [69], their main challenges are related to the limited personnel to participate in numerous international trials, while also handling high medical demands. Multidisciplinary assistance has also been implemented by Italian NMD clinical centres beyond NEMO, with the main difficulty being the need to logistically fit this care approach within the general hospital context.

The demonstrated capability to provide quality assistance made many of these centres eligible to be included in the Euro-NMD ERN [60].

\section{Innovation and therapies}

The increased clinical knowledge in the field of DMD and SMA gained thanks to the Telethon-UILDM projects contributed to the clinical trial design for innovative therapies, working on OM adopted in international trials [36, 37] or contributing to a new statistical approach for trial data evaluation [54-56]. Telethon made agreements to share data for nonexclusive use with third parties, including industry. Other agreements with industry were based on unconditional support provided to Telethon to make the long-term natural history data collection sustainable. Natural history data collected by the Italian DMD clinical network supported international efforts focused on the interpretation of clinical trial data [36, 54-56] and contributed to the discussion with regulators [53].

Moreover, the high level of standardisation of the clinical measures and care reached by several Italian NMD centres has been an enabling factor to favour their inclusion in international trials testing innovative therapies on DMD and SMA, allowing the participation of many Italian patients in these trials. Several centres, including NEMO centres, also participated in early access to therapy programs, i.e. for SMA [70] and are now collecting real world data into highly structured registries.

\section{Cultural change}

This path towards "Value to patients" has had an indirect impact on other domains as well (Fig. 2), such as dissemination of good practices on data sharing, better communication between clinicians and POs, and patient empowerment, all ultimately contributing to a cultural shift towards the involvement of multiple stakeholders in a co-creation process on healthcare research. Notably, not only UILDM has been the driver for the ideation, development, and funding of this clinical research program, but it also became a main actor in the development of the unique models of the NEMO clinical centres $[5,6]$ and of the legal entity that holds the stewardship of the NMD registry platform [48]. The example of UILDM has been followed by other POs that contributed to support the clinical research programs dedicated to their disease of interest, and/ or are partners in the NEMO enterprise and the NMD registry platform initiative.

\section{Key factors for the success of the initiative}

A rigorous peer review process allowed to support the research activity of many excellent clinical scientists, who enthusiastically participated in the funded projects bringing new ideas and their leadership and expertise. Continuity of the financial support and strong management implemented also considering the lessons learned contributed to the growth of a strong clinical network. Although public resources have always been rather limited, the Italian national health system has provided support, with structural funds allocated to the clinical units, for instance for the salary of principal investigators and to cover biomedical examinations that are part of the routine patient care. The support provided by NMD POs, not only by providing funds and structural platforms, but also through continuous dialogue and sharing of knowledge was fundamental for the implementation of the studies.

In the last decade, the international scenario on clinical research on NMDs has changed radically, with a big step forward in trial readiness and with the advent of innovative therapeutic approaches for diseases such as DMD and SMA [4]. This focused funding program provided the opportunity for Italian experts to contribute to an international cross-fertilisation process by leveraging a vast clinical network and patient cohorts nationwide and for Italian patients to participate in international trials and benefit from early access to therapies. 


\section{Challenges and opportunities}

Although the Telethon-UILDM initiative was based on identified priorities and focused on specific diseases and topics, essentially it has been an investigator-driven extramural research funding. A typical consequence of bottom-up investments is that funders' priorities do not always match those of investigators, who propose research that better suits their expertise and interests [71]. This was at least partially the case with this program, where some important issues of great relevance to the NMD patient community remained unaddressed, such as implementation of home care support or management of specific medical needs. One way out is to set strict priorities in advance by clearly explaining in the call for grant applications what kind of research funders are willing to support, although this does not guarantee a positive and successful response from applicants. In the attempt to steer the research agenda and attract new medical competences within the clinical network, the call has been revised over the years, becoming more focused on the diseases and medical fields most relevant to UILDM.

Running clinical studies that involve large research networks remains a challenge due to the limitation of economic resources that can be invested annually. A sustainability plan that has already proven its feasibility has involved partnering with pharmaceutical companies interested in developing therapies for NMD, particularly regarding the collection of data that may be relevant to regulators' decision making [53-56]. This multi-stakeholder approach would be a convenient opportunity for all parties, but it also implies a cultural shift towards unconditional support by companies to academic clinical activities that are essential to prepare the ground for future trials, where return may not be immediate [72]. Importantly, it can also contribute to promoting training and career development of junior clinical scientists, preparing the ground for the clinical research of the future.

\section{Limitations of this analysis}

This analysis was based on internal scrutiny and management of Telethon grants, publications acknowledging the Telethon grants, and information nationally or internationally publicly available. Despite an accurate monitoring of the results of each project after grant completion to understand its impact on patients and healthcare, the information reported may be partial and the elaborated picture incomplete.

For privacy reasons, the authors did not have direct access to the individual Customer Satisfaction feedbacks of patients admitted at the NEMO clinical centres. Information in the form of aggregated data was publicly available from the NEMO annual Impact Report 2019 [9]; the authors are not responsible for the methods applied by professionals of the NEMO centres for the analysis of data derived from such Customer Satisfaction questionnaires.

\section{Conclusions}

The funds awarded within the Telethon-UILDM calls and through topic-related ad hoc grants have contributed to support a network of physicians who actively collaborated on several clinical research projects, sharing their experience, and adopting common medical care and research approach to NMDs. The initial idea of Telethon and UILDM that led to the development of this program in 2001 proved to be very valid and visionary, as demonstrated by the consequent expansion and cultural growth of the Italian NMD clinical network thanks to this support. While training and development of scientific competences are matter for scientific societies, this strategic program has contributed to a paradigm shift on issues such as data sharing and on the implementation of patient-centric research and multidisciplinary care, at least in Italy. Furthermore, the increased clinical knowledge on NMDs contributed to stir international discussion within the disease community and with regulators, facilitating the development of innovative therapies. This demonstrates that charities and POs may synergise with other stakeholders and contribute to orphan medicine development even when these don't derive from their own internal pipeline. Although each country has its own health research working models, sharing this experience and lessons learned can therefore be beneficial to other charities and POs that want to promote clinical research towards the care of patients with rare diseases.

The advent of innovative therapeutics has raised lot of hope, with therapies already available to patients for a few diseases, such as DMD and SMA. However, much work remains to be done. First of all, much information is still lacking for correct interpretation of trial results; issues like natural history expanded to a wider-age group, the role of confounding factors (such as genetic modifiers, multi-organ involvement, etc.), and biomarker validation require further investigation. Furthermore, one must consider that NMDs are part of a broad category of diseases; clinical characterisation and natural history are still lacking for many of them, and the experience gained on DMD and SMA should guide research on other NMDs as well. Finally, we must be sought for the daily medical needs of those patients who do not fully benefit from advanced therapies, as they are treated when the disease is no longer at a very early stage or do not have access to these therapies, due to their genotype or for other reasons. While these topics may require even more strict definition of priorities within the calls for research proposals, the investigator-driven nature of this funding 
scheme remains very valid and can help attract innovative (and sometimes unpredictable) ideas and new expertise into the field.

\begin{abstract}
Abbreviations
CMT: Charcot-Marie-Tooth disease; CTAP: Collaborative Trajectory Analysis Project; DMD: Duchenne muscular dystrophy; NEMO: NEuroMuscular Omni centre; NIH: National Institutes of Health; NMD: Neuromuscular disorder; OM: Outcome measure; PO: Patient organisation; QoL: Quality of life; RCR: Relative citation ratio; SMA: Spinal muscular atrophy; TREAT-NMD: Translational Research in Europe-Assessment and Treatment of NeuroMuscular Diseases; TTR: Transthyretin; UILDM: Unione italiana lotta alla distrofia muscolare.
\end{abstract}

\section{Acknowledgements}

We are grateful to our advisors and all reviewers who contributed to this program with their evaluations and constructive comments to improve the scientific content of the projects. We thank Valeria Sansone (NEMO centre, Milan, Italy), Davide Pareyson ("C. Besta" Neurological Institute, Milan, Italy), and Mary Wang (Fondazione Telethon) for critical reading of the manuscript and helpful suggestions. We acknowledge the support of Barbara La Torraca and Milena Vitale (Fondazione Telethon) in the preparation of Figs. 1 and 3 respectively.

\section{Authors' contributions}

AA outlined the structure of the paper and wrote the manuscript; DB and SP contributed to the bibliometric analysis; all contributed to the management of the activities described and with critical reading and suggestions on the manuscript. All authors read and approved the final manuscript.

\section{Funding}

The results described derive from research projects which have been funded by Telethon and UILDM, within the Telethon-UILDM funding scheme. The ad hoc sponsored projects have been funded thanks to the economic support provided by the Italian POs Famiglie SMA and Mitocon. Additional support was received by the "collaborative Trajectory Analysis Project" (cTAP), Sarepta Therapeutics Inc, BioMarin Pharmaceutical Inc., and Akcea Therapeutics. The Funders had no role in the study design, data collection and analysis, decision to publish, or preparation of this manuscript.

\section{Availability of data and materials}

The PubMed Identifier dataset used for the analyses reported in the text and in Tables 2, 3 and 4 is available from the corresponding author. Please contact the corresponding author for data requests.

\section{Declarations}

\section{Ethics approval and consent to participate}

Not applicable.

\section{Consent for publication}

Not applicable.

\section{Competing interests}

The authors declare that they have no competing interests.

\section{Author details}

${ }^{1}$ Fondazione Telethon, Via Poerio 14, Milan, Italy. ${ }^{2}$ B.E.A. Consulting, Milan, Italy. ${ }^{3}$ UILDM, Unione Italiana Lotta alla Distrofia Muscolare, Padua, Italy.

Received: 14 April 2021 Accepted: 19 September 2021

Published online: 02 October 2021

\section{References}

1. Monaco L, Faccio L. Patient-driven search for rare disease therapies: the Fondazione Telethon success story and the strategy leading to Strimvelis. EMBO Mol Med. 2017;9(3):289-92.
2. EMA authorisation of Libmeldy, Autologous CD34+ cells encoding ARSA gene. https://www.ema.europa.eu/en/medicines/human/EPAR/libmeldy. Accessed 30 July 2021.

3. Pareyson D, Saveri P, Pisciotta C. New developments in CharcotMarie-Tooth neuropathy and related diseases. Curr Opin Neurol. 2017;30(5):471-80.

4. Mercuri E, Bönnemann CG, Muntoni F. Muscular dystrophies. Lancet. 2019;394(10213):2025-38.

5. Centro clinico NEMO website. https://centrocliniconemo.it/. Accessed 30 July 2021.

6. Centro clinico NEMO annual Impact Report 2019. https://f.hubsp otusercontent00.net/hubfs/4358056/Bilancio\%20Sociale\%202019.pdf. Accessed 30 July 2021.

7. Web of Science website. https://clarivate.com/webofsciencegroup/. Accessed 26 Feb 2021.

8. Europe PubMed Central website. https://europepmc.org/. Accessed 26 Feb 2021.

9. Hutchins BI, Yuan X, Anderson JM, Santangelo GM. Relative citation ratio $(R C R)$ : a new metric that uses citation rates to measure influence at the article level. PLoS Biol. 2016;14(9):e1002541.

10. NIH iCite website. https://icite.od.nih.gov/analysis. Accessed 30 July 2021.

11. DORA website. http://www.ascb.org/dora/. Accessed 30 July 2021.

12. Padua L, Pareyson D, Aprile I, Cavallaro T, Quattrone A, Rizzuto N, et al. Natural history of CMT1A including QoL: a 2-year prospective study. Neuromuscul Disord. 2008;18(3):199-203.

13. Graziano A, Bianco F, D'Amico A, Moroni I, Messina S, Bruno C, et al. Prevalence of congenital muscular dystrophy in Italy: a population study. Neurology. 2015;84(9):904-11.

14. Fattori F, Maggi L, Bruno C, Cassandrini D, Codemo V, Catteruccia M, et al. Centronuclear myopathies: genotype-phenotype correlation and frequency of defined genetic forms in an Italian cohort. J Neurol. 2015;262(7):1728-40.

15. Mancuso M, Orsucci D, Angelini C, Bertini E, Carelli V, Comi GP, et al. "Mitochondrial neuropathies": a survey from the large cohort of the Italian Network. Neuromuscul Disord. 2016;26(4-5):272-6.

16. Magri F, Nigro V, Angelini C, Mongini T, Mora M, Moroni I, et al. The Italian limb girdle muscular dystrophy registry: relative frequency, clinical features, and differential diagnosis. Muscle Nerve. 2017;55(1):55-68.

17. Astrea G, Romano A, Angelini C, Antozzi CG, Barresi R, Battini R, et al. Broad phenotypic spectrum and genotype-phenotype correlations in GMPPB-related dystroglycanopathies: an Italian cross-sectional study. Orphanet J Rare Dis. 2018;13(1):170.

18. Pane M, Palermo C, Messina S, Sansone VA, Bruno C, Catteruccia M, et al. An observational study of functional abilities in infants, children, and adults with type 1 SMA. Neurology. 2018;91(8):e696-703.

19. Coratti G, Brogna C, Norcia G, Ricotti V, Abbott L, D'Amico A, et al. Longitudinal natural history in young boys with Duchenne muscular dystrophy. Neuromuscul Disord. 2019:29(11):857-62.

20. Vercelli L, Mele F, Ruggiero L, Sera F, Tripodi S, Ricci G, et al. A 5-year clinical follow-up study from the Italian National Registry for FSHD. J Neurol. 2020. https://doi.org/10.1007/s00415-020-10144-7.

21. Savarese M, Di Fruscio G, Mutarelli M, Torella A, Magri F, Santorelli FM, et al. MotorPlex provides accurate variant detection across large muscle genes both in single myopathic patients and in pools of DNA samples. Acta Neuropathol Commun. 2014;11(2):100

22. Savarese M, Di Fruscio G, Torella A, Fiorillo C, Magri F, Fanin M, et al. The genetic basis of undiagnosed muscular dystrophies and myopathies: results from 504 patients. Neurology. 2016:87(1):71-6.

23. Pareyson D, Saveri P, Piscosquito G. Charcot-Marie-Tooth disease and related hereditary neuropathies: from gene function to associated phenotypes. Curr Mol Med. 2014;14(8):1009-33.

24. Ricci G, Mele F, Govi M, Ruggiero L, Sera F, Vercelli L, et al. Large genotypephenotype study in carriers of D4Z4 borderline alleles provides guidance for facioscapulohumeral muscular dystrophy diagnosis. Sci Rep. 2020;10(1):21648.

25. Russo M, Obici L, Bartolomei I, Cappelli F, Luigetti M, Fenu S, et al. ATTRv amyloidosis Italian Registry: clinical and epidemiological data. Amyloid. 2020;27(4):259-65.

26. Grandis M, Obici L, Luigetti M, Briani C, Benedicenti F, Bisogni G, et al. Recommendations for pre-symptomatic genetic testing for hereditary 
transthyretin amyloidosis in the era of effective therapy: a multicenter Italian consensus. Orphanet J Rare Dis. 2020;15:348.

27. TREAT-NMD website. https://treat-nmd.org/. Accessed 30 July 2021.

28. Mercuri E, Coratti G, Messina S, Ricotti V, Baranello G, D'Amico A, et al. Revised North Star Ambulatory Assessment for young boys with duchenne muscular dystrophy. PLoS ONE. 2016;11(8):e0160195.

29. Mazzone ES, Coratti G, Sormani MP, Messina S, Pane M, D'Amico A et al. Timed rise from floor as a predictor of disease progression in duchenne muscular dystrophy: an observational study. PLOS ONE. 2016;11(3):e0151445.

30. Inherited Neuropathy Consortium (INC) website. https://www.rarediseas esnetwork.org/cms/inc. Accessed 30 July 2021.

31. Mori L, Signori A, Prada V, Pareyson D, Piscosquito G, Padua L, et al. Treadmill training in patients affected by Charcot-Marie-Toothneuropathy: results of a multicenter, prospective, randomized, single-blind, controlled study. Eur J Neurol. 2020;27(2):280-7.

32. Fridman V, Sillau S, Acsadi G, Bacon C, Dooley K, Burns J, et al. A longitudinal study of CMT1A using Rasch analysis based CMT neuropathy and examination scores. Neurology. 2020;94(9):e884-96.

33. Mayhew A, Mazzone ES, Eagle M, Duong T, Ash M, Decostre V, et al. Development of the performance of the upper limb module for Duchenne muscular dystrophy. Performance of the Upper Limb Working Group. Dev Med Child Neurol. 2013;55(11):1038-45.

34. Mayhew AG, Coratti G, Mazzone ES, Klingels K, James M, Pane M, et al. Performance of upper limb module for Duchenne muscular dystrophy. Dev Med Child Neurol. 2020;62(5):633-9.

35. Klingels K, Mayhew AG, Mazzone ES, Duong T, Decostre V, Werlauff U, et al. Development of a patient-reported outcome measure for upper limb function in Duchenne muscular dystrophy: DMD Upper Limb PROM. Dev Med Child Neurol. 2017;59(2):224-31.

36. Mendell JR, Goemans N, Lowes LP, Alfano LN, Berry K, Shao J, et al. Longitudinal effect of eteplirsen versus historical control on ambulation in Duchenne muscular dystrophy. Ann Neurol. 2016;79(2):257-71.

37. Ricotti V, Selby V, Ridout D, Domingos J, Decostre V, Mayhew A, et al, Respiratory and upper limb function as outcome measures in ambulant and non-ambulant subjects with Duchenne muscular dystrophy: a prospective multicentre study. Neuromuscul Disord. 2019;29(4):261-8

38. Pane M, Fanelli L, Mazzone ES, Olivieri G, D'Amico A, Messina S, et al. Benefits of glucocorticoids in non-ambulant boys/men with Duchenne muscular dystrophy: a multicentric longitudinal study using the performance of upper limb test. Neuromuscul Disord. 2015;25(10):749-53.

39. Pane M, Coratti G, Brogna C, Mazzone ES, Mayhew A, Fanelli L, et al. Upper limb function in Duchenne muscular dystrophy: 24 month longitudinal data. PLoS One. 2018;13(6):e0199223.

40. Sansone VA, Panzeri M, Montanari M, Apolone G, Gandossini S, Rose MR et al. Italian validation of INQoL, a quality of life questionnaire for adults with muscle diseases. Eur J Neurol. 2010;17(9):1178-87.

41. Magliano L, Patalano M, Alessandra Sagliocchi A, Scutifero M, Zaccaro A, D'Angelo MG, et al. Burden, professional support, and social network in families of children and young adults with muscular dystrophies. Muscle Nerve. 2015:52(1):13-21.

42. Martinuzzi A, Liava A, Trevisi E, Frare M, Tonon C, Malucelli E, et al. Randomized, placebo-controlled, double-blind pilot trial of ramipril in McArdle's disease. Muscle Nerve. 2008;37(3):350-7.

43. Pareyson D, Reilly MM, Schenone A, Fabrizi GM, Cavallaro T, Santoro L, et al. Ascorbic acid in Charcot-Marie-Tooth disease type 1A (CMTTRIAAL and CMT-TRAUK): a double-blind randomised trial. Lancet Neurol. 2011;10(4):320-8

44. Parenti G, Fecarotta S, La Marca G, Rossi B, Ascione S, Donati MA, et al. A chaperone enhances blood a-glucosidase activity in Pompe disease patients treated with enzyme replacement therapy. Mol Ther. 2014:22(11):2004-12.

45. Merlini L, Sabatelli P, Armaroli A, Gnudi S, Angelin A, Grumati P, et al. Cyclosporine A in Ullrich congenital muscular dystrophy: long-term results. Oxid Med Cell Longev. 2011;66:139194.

46. Registro Italiano dei pazienti con malattie neuromuscolari website. http:// www.registronmd.it/?page_id=461. Accessed 30 July 2021.

47. European General Data protection Regulation website. https://gdpr.eu. Accessed 30 July 2021.

48. Ambrosini A, Calabrese D, Avato FM, Catania F, Cavaletti G, Pera MC, et al. The Italian neuromuscular registry: a coordinated platform where patient organizations and clinicians collaborate for data collection and multiple usage. Orphanet J Rare Dis. 2018;13(1):176.

49. Pisciotta C, Calabrese D, Santoro L, Tramacere I, Manganelli F, Fabrizi GM, et al. Pregnancy in Charcot-Marie-Tooth disease: data from the Italian CMT national registry. Neurology. 2020;95(24):e3180-9.

50. Magliano L, Obici L, Sforzini C, Mazzeo A, Russo M, Cappelli F, et al. Psychosocial burden and professional and social support in patients with hereditary transthyretin amyloidosis (ATTRv) and their relatives in Italy. Orphanet J Rare Dis. 2021;16(1):163.

51. Registro italiano dei pazienti mitocondriali website. https://www.mitoc on.it/registro-pazienti/. Accessed 30 July 2021.

52. Filosto M, Cotti Piccinelli S, Lamperti C, Mongini T, Servidei S, et al. Muscle pain in mitochondrial diseases: a picture from the Italian network. Neurol. 2019;266(4):953-9.

53. Straub V, Balabanov P, Bushby K, Ensini M, Goemans N, De Luca A, et al. Stakeholder cooperation to overcome challenges in orphan medicine development: the example of Duchenne muscular dystrophy. Lancet Neurol. 2016;15(8):882-90.

54. Mercuri E, Signorovitch JE, Swallow E, Song J, Ward SJ; DMD Italian Group; Trajectory Analysis Project (CTAP). Categorizing natural history trajectories of ambulatory function measured by the 6-minute walk distance in patients with Duchenne muscular dystrophy. Neuromuscul Disord. 2016;26(9):576-83 [Corrigendum Neuromuscular Disorders 2017 May;27(5):e1].

55. Brogna C, Coratti G, Pane M, Ricotti V, Messina S, D'Amico A, et al. Longterm natural history data in Duchenne muscular dystrophy ambulant patients with mutations amenable to skip exons 44, 45, 51 and 53. PLoS ONE. 2019;14(6):e0218683. [PLOS ONE. Correction: 2019;14(7):e0220714].

56. Goemans N, Signorovitch J, Sajeev G, Yao Z, Gordish-Dressman H, et al. Suitability of external controls for drug evaluation in Duchenne muscular dystrophy. Neurology. 2020;95(10):e1381-91.

57. Wang CH, Finkel RS, Bertini ES, Schroth M, Simonds A, Wong B, et al. Consensus statement for standard of care in spinal muscular atrophy. J Child Neurol. 2007;22(8):1027-49.

58. Bushby K, Finkel R, Birnkrant DJ, Case LE, Clemens PR, Cripe L, et al. Diagnosis and management of Duchenne muscular dystrophy, part 1: diagnosis, and pharmacological and psychosocial management. Lancet Neurol. 2010;9(1):77-93.

59. Bushby K, Finkel R, Birnkrant DJ, Case LE, Clemens PR, Cripe L, et al. Diagnosis and management of Duchenne muscular dystrophy, part 2: implementation of multidisciplinary care. Lancet Neurol. 2010;9(2):177-89.

60. EURO-NMD European Reference network website: European Reference Network -EURO-NMD—European Reference Network for Neuromuscular Diseases (ern-euro-nmd.eu). Accessed 30 July 2021.

61. Miller KL, Mueller C, Liu G, Miller Needleman Kl, Maynard J. FDA orphan products clinical trial grants: assessment of outcomes and impact on rare disease product development. Orphanet J Rare Dis. 2020;15(1):234.

62. Sacristán JA. Clinical research and medical care: towards effective and complete integration. BMC Med Res Methodol. 2015;9(15):4.

63. Kristensen $\mathrm{N}$, Nymann $\mathrm{C}$, Konradsen $\mathrm{H}$. Implementing research results in clinical practice - the experiences of healthcare professionals. BMC Health Serv Res. 2016;16:48.

64. Horton R, Lucassen A. Genomic testing in healthcare: a hybrid space where clinical practice and research need to co-exist. Expert Rev Mol Diagnost. 2019;19(11):963-7.

65. D'Amico A, Catteruccia M, Baranello G, Politano L, Govoni A, Previtali SC, et al. Diagnosis of Duchenne Muscular Dystrophy in Italy in the last decade: critical issues and areas for improvements. Neuromuscul Disord. 2017;27(5):447-51.

66. Giugliano T, Savarese M, Garofalo A, Picillo E, Fiorillo C, D'Amico A, et al. Copy number variants account for a tiny fraction of undiagnosed myopathic patients. Genes. 2018:9(11):524

67. Pera MC, Coratti G, Berti B, D'Amico A, Sframeli M, Albamonte E, et al. Diagnostic journey in spinal muscular atrophy: Is it still an odyssey? PLoS ONE. 2020;15(3):e0230677.

68. Ambrosini A, Quinlivan R, Sansone VA, Meijer I, Schrijvers G, Tibben A et al. "Be an ambassador for change that you would like to see": a call to action to all stakeholders for co-creation in healthcare and medical research to improve quality of life of people with a neuromuscular disease. Orphanet J Rare Dis. 2019;14(1):126. 
69. Sansone VA, Albamonte E, Salmin F, Casiraghi J, Pirola A, Bettinelli M, et al. Intrathecal nusinersen treatment for SMA in a dedicated neuromuscular clinic: an example of multidisciplinary and integrated care. Neurol Sci. 2019;40(2):327-32.

70. Messina S, Pane M, Sansone V, Bruno C, Catteruccia M, Vita G, et al. Expanded access program with Nusinersen in SMA type I in Italy: strengths and pitfalls of a successful experience. Neuromuscul Disord. 2017;27(12):1084-6.

71. Cartier Y, Creatore MI, Hoffmann SJ, Potvin L. Priority-setting in public health research funding organisations: an exploratory qualitative study among five high-profile funders. Health Res Policy Syst. 2018;16:53.
72. Lochmüller H, Ramirez AN, Kakkis E. Disease monitoring programs of rare genetic diseases: transparent data sharing between academic and commercial stakeholders. Orphanet J Rare Dis. 2021;16(1):141.

\section{Publisher's Note}

Springer Nature remains neutral with regard to jurisdictional claims in published maps and institutional affiliations.
Ready to submit your research? Choose BMC and benefit from:

- fast, convenient online submission

- thorough peer review by experienced researchers in your field

- rapid publication on acceptance

- support for research data, including large and complex data types

- gold Open Access which fosters wider collaboration and increased citations

- maximum visibility for your research: over $100 \mathrm{M}$ website views per year

At BMC, research is always in progress.

Learn more biomedcentral.com/submissions 